\title{
Understanding the idea of 'grant dependency' in the voluntary and community sector
}

\author{
Rob Macmillan* \\ Sheffield Hallam University
}

\begin{abstract}
The sustainability of voluntary organisations and community groups has become an increasingly salient aspect of recent debates in the voluntary sector in the U.K., alongside a growing interest in the pursuit of more entrepreneurial community-based activity. These developments have coincided with the emergence of new ways of framing discussions around finance and funding in the sector. This article begins a process of unravelling and making sense of these new discourses. It takes as its starting point an illustrative discussion of the emergence and use of the idea of 'grant dependency' and provides a theoretical account of how and why this new language has developed.
\end{abstract}

Keywords: third sector, funding, grant dependency, discourse, social investment.

\section{Introduction}

How is it that seemingly many more people within and beyond the voluntary and community sector now talk about the idea of 'grant dependency'? In everyday use the term implies a shorthand critique and judgement of those voluntary organisations which continue to seek and rely upon grant funding. Whilst we may wish to seek more clarification about what 'grant dependency' might look like in practice, this paper asks how the term crept up on us, so that in the space of just a few years it appears to have become embedded in the conventional ways people speak about the sector.

The paper is intended to be the start of a process of attempting to make some sense of the contours of this new discourse. In so doing it uses the idea of 'grant dependency' as a way of setting out a research agenda which aims to understand how new prevailing wisdom is formed, circulated and reinforced in the voluntary and community sector.

Of course affording a place for ideas in the development of the sector is not new. For 
p.31. Understanding the idea of 'grant dependency' in the voluntary and community sector

example, Kendall's (2003) account of mainstreaming the voluntary sector in the UK policy process from the second half of the 1990s notes not only the development of the very idea of a 'sector', but also the potential importance for policymakers of key voluntary sector indicators apparently 'going the wrong way'. Here Kendall argues that "Facts do not speak for themselves: it is the interpretation of facts that matters" (Kendall 2003: 51, emphasis added).

After noting some features of the current voluntary and community sector funding context, the paper considers the emergence and use of the idea of 'grant dependency', before concluding with some thoughts about a possible research agenda informed theoretically by Bourdieu's social theory and the notion of 'discursive institutionalism' in political science.

\section{The voluntary and community sector funding context}

Finance and funding issues remain perennial concerns of voluntary organisations and community groups (Macmillan, 2004; p. 9-12; Blackmore, 2005; p. 27), revolving around overall availability of resources, the struggle to secure continuation resources, and the transactions costs and conditions associated with generating, coordinating and managing resources. Although the overall financial sustainability of voluntary organisations and community groups is an ongoing concern, the issue has also become increasingly salient given the UK government's project to enhance the role of the voluntary and community sector in delivering public services (HM Treasury, 2002; Home Office, 2004).

It is worthwhile distinguishing between macro and micro levels in any analysis of voluntary and community sector funding. At a macro level, levels of overall funding have continued to attract concern within and beyond the sector. For example, a recent comprehensive overview of the funding landscape argues that:

The voluntary and community sector will continue to grow in size, especially at the top and bottom of scale as measured by annual income. There will be no shortage of demand for funds from all sources as the number and ambitions of charities increase; competition between charities will, therefore, intensify but there will also be increased pressure (on funders and on fund-seekers) to make every penny work harder, to encourage ingenuity in financing work, to demonstrate efficiency and cost effectiveness, to share or pool resources and efforts (Carrington, 2005; p. 110).

Recent trends suggest that the increase in overall voluntary and community sector income is primarily due to an increase in the number of organisations, rather than increasing income for individual organisations Average incomes for all organisations were either static or falling (Wainwright et al, 2006). The 2005/6 Strategic Analysis produced by the National Council for Voluntary Organisations (NCVO) reports:

There is continuing concern that a number of important income streams are likely to be rationalized or reduced, whilst competition for finance (whether voluntary or earned) is likely to intensify. Mid-sized organizations continue to bear the brunt of falling income, suggesting a continuing polarization of the sector in terms of income (Griffiths, et al. 2005; p. 6-7). 
p.32. Understanding the idea of 'grant dependency' in the voluntary and community sector

In some regions the withdrawal or reconfiguration of a number of funding streams has been described as a potential 'cliff edge' with major implications for those voluntary organisations and community groups that have grown or are otherwise reliant on significant regeneration funding (Shutt and Kumi-Ampofo, 2005; Chapman et al, 2006).

At a more micro level, the task of mitigating the apparent vulnerability of voluntary organisations and community groups to short term, stop-start funding has become an important aspect of the debate around developments in the sector. A national 'Finance hub' has been established as part of the UK government's ChangeUp infrastructure programme in order to help towards a vision of "VCOs which are effective and independent because they are financially sustainable" (Finance Hub, 2005). Meanwhile the 'Sustainable Funding Project' at NCVO has developed a range of interventions, such as seminars, the website, books, guidance notes and diagnostic tools since it was established in 2000 with the aim of:

encouraging and enabling voluntary and community organisations to explore and exploit a full range of funding options to develop a sustainable funding mix. (http://www.ncvo-vol.org.uk/sfp/?id=2091, accessed 23.3.06).

Its website describes the more challenging environment in stark terms, providing the clearest hint that the terms of the debate on funding are changing:

We live in a cold climate for charity fundraising. Lottery ticket sales have declined since launch, resulting in less funding flowing to voluntary and community organizations, European funding will migrate to new member states after 2006. Charitable giving shows no signs of significant growth. Business giving remains low. But new opportunities are emerging too. Increasingly charities are being told to move away from grant dependency, become more business like, earn income, develop an asset base and consider loan finance. And opportunities for delivering public services are increasing (http://www.ncvo-vol.org.uk/sfp/?id=2091, accessed 23.3.06, emphasis added).

\section{The emergence of the idea of 'grant dependency'}

The argument here is that the emergence of a more challenging funding environment has coincided with the development of new ways of framing discussions around finance and funding in the sector. A new double-sided language appears to have taken hold, with notions of 'investment' and 'returns' on the one hand counter-posed against 'traditional' grants and, in some formulations, 'grant dependency' on the other.

On one side, a business-focused language of assets, investments and returns seems to be flourishing. Carrington (2005; p. 110) notes "That the language of 'investment' is used increasingly by both funder and funded is not just rhetoric". Unwin (2004) helpfully distinguishes between three funding modes: 'giving' (grants), 'shopping' (contracts and procurement) and 'investing'. The latter, she notes, has “..has the specific intention of producing a long-term outcome, usually after the period of the funding....requires a closer relationship with the recipient....[and] will usually be accompanied by some other form of support or guidance..." (Unwin, 2004; p. 66). 
p.33. Understanding the idea of 'grant dependency' in the voluntary and community sector

On the other side of this development, however, grant funding also appears to be undergoing some form of reassessment. Unwin (2004; p. 53) notes that 'giving' has, ironically, gained a poor reputation in recent years. Carrington (2005; p. 103, 106-108) refers to "the dominance of a grants culture - which can have perverse and expensive consequences" including: "project-itis', short term funding with demands for unrealistic 'exit strategies', under-funded initiatives, lack of incentives to perform effectively and high transaction costs. The associated concept of 'grant dependency' concentrates on the development of cultures and practices within voluntary organisations, as seen in this example from a recent report, tellingly entitled 'From asking to earning':

The funding environment is tougher than ever. This is making it increasingly important for voluntary and community organisations (VCOs) to diversify their income streams. In recent years, there has been much focus on the "grant dependency culture". Such dependency forces organisations to rely too heavily on a single source of funding and forces them to constantly seek out the next tranche of short term funding. In short, grant dependency can make organisations both weak and vulnerable (Palmer and Mornement, 2005: p. 73, emphasis added).

As a further illustration of the ways in which the term 'grant dependency' is being used in practice, an initial internet search of websites and documents deploying the term suggests some intriguing results, as shown in Table 1. A number of recurring themes seem to arise, including references to:

- reducing, 'moving away from', 'moving beyond' and escaping grant dependency

- the necessity of such a shift given the external funding environment

- contrasting short term (grant dependency) and long term (sustainability)

- the idea of self-sufficiency and independence versus dependency and 'spoon feeding'.

From this, we can discern some key elements of how 'grant dependency' is being constructed. Of course in no way can an internet search substitute for a full analysis of the new discourses around finance in the sector. This would require a deeper engagement with a wider range of sources in order to gain a sense of prevailing discourses. But it does perhaps provide an indication that there is something worthy of further exploration.

The idea appears to have two main features: a judgement regarding the funding mix of individual organisations, based on a factual assessment of the number, type and predominance of different funding sources, coupled with an assessment of the behavioural consequences of such a funding mix; in particular the development of an identifiable organisational culture that results from different portfolios of funding. 
p.34. Understanding the idea of 'grant dependency' in the voluntary and community sector

\section{Table 1: Grant dependency 'googled'}

An internet search on 'grant dependency' (23.3.06) using Google yielded 'about 9,700,000 hits' on the web, of which 'about 392,000 hits' were UK only. The results are mainly about the voluntary and community sector, though some also referred to support for small business, and curiously, the UK solar water heating market.

Selected results from the first three pages (30 hits) of the search are shown below:

1. NACVS - 'reducing LIO grant dependency'

2. NCVO - 'reducing grant dependency'

3. Futurebuilders - 'has been able to provide an investment package designed to support Derwent Stepping Stones in its move away from grant dependency'

4. Development Trusts Association - 'organisations on a transformative journey, reducing grant dependency, increasing trading, and achieving higher social impacts'

5. Allavida - 'how can non profits escape grant dependency?'

6. Bridge House Trust - 'the development of asset bases and other alternatives to grant dependency'

7. Local Investment Fund - 'By providing loan finance, LIF enables community organisations to move from grant dependency and towards self-sufficiency'

8. ODPM - 'Today's announcement will help more community enterprises to expand the business side of their operations, and to move away from grant dependency.'

9. SCVO - 'it is widely recognised that the sector must move from a culture of grant dependency to one of attracting and retaining investment'

10. Sheffield City Council - 'The aim is to help shift organisations away from short-term grant dependency to longer-term financial stability'

The way this language is used seems to mirror quite closely the parallel discussions of 'benefit dependency' and 'welfare dependency', involving the need to 'stand on your own two feet' independently of external subsidy or support (Dean and Taylor Gooby, 1992). It is as if voluntary organisations or groups are being treated as if they were analogous to individuals and households.

Overall, website references to 'grant dependency' tend to operate on an assumption that it exists, that it is problematic, and that organisations should take steps or need help to overcome or move away from it. Few of the references found seem to question the existence of grant dependency, though as we have seen some refer to 'so-called' grant dependency or as something about which there is growing interest or debate. This is a particularly fascinating point, because it is not clear that the issue has been studied in depth. To date no references have been found which provide research evidence of the existence of 'grant dependency'. And yet it is referred to as though it exists. Hence, it may not matter so much whether 'grant dependency' exists, rather what matters is the extent to which policy makers and practitioners make decisions, develop policies and programmes and act as if it exists. I return to this theme shortly. 


\section{Making sense of 'grant dependency'}

How can we understand and explain the emergence of the idea of 'grant dependency'? The contention here is that the discussion cannot meaningfully be divorced from a much wider set of debates in social policy regarding the 'Third Way', and particularly its deployment of a 'social investment perspective' (Giddens 1998, Lister 2004, Dobrowolsky and Jensen 2005). My suggestion is that this has become a prevailing climate of opinion, from which discussion of new approaches to financing the voluntary and community sector implicitly draw. In the social investment perspective public intervention is justified in terms of 'investments' designed to yield particular dividends over time:

The social investment perspective...frames social policy expenditures as investments rather than expenditures, forecasting future dividends from spending now... (Dobrowolsky and Jensen, 2005; p. 203).

In short, proponents of social investment perspectives argue that the state should play an enabling or catalytic role in developing the capabilities of individuals, communities and organisations. Lister (2004) identifies eight key elements of the emerging 'social investment state'. Four of these are listed in Table 2 below, chosen not only because they represent core themes of the perspective, but also because there are some interesting parallels with debates in the voluntary and community sector on sustainable funding. By analogy, many of the themes of the social investment state, as applied to individuals and households, can be applied to voluntary organisations and community groups.

\section{Table 2: The Social Investment State and sustainable funding compared}

\begin{tabular}{lll}
\hline \multicolumn{1}{c}{$\begin{array}{c}\text { Elements of a 'social } \\
\text { investment state' }\end{array}$} & $\begin{array}{c}\text { Extension (by analogy) to debates on sustainability in } \\
\text { the voluntary and community sector }\end{array}$ \\
\hline $\begin{array}{l}\text { 1. A discourse of social investment } \\
\text { in place of 'tax and spend' }\end{array}$ & $\begin{array}{l}\text { Voluntary and community sector 'finance' (not } \\
\text { funding) 'beyond grants', including trading, } \\
\text { investment and loans. }\end{array}$ \\
\hline 2. $\quad \begin{array}{l}\text { Investment in human and social } \\
\text { capital }\end{array}$ & $\begin{array}{l}\text { Investment in, encouragement of and support for } \\
\text { organisational capacity building, training, networking } \\
\text { and collaboration. }\end{array}$ \\
\hline 3. $\quad$ Future focused & $\begin{array}{l}\text { Strategic planning, a focus on organisations looking } \\
\text { to the future and anticipating change, rather than }\end{array}$ \\
& $\begin{array}{l}\text { being preoccupied with the here and now, and the } \\
\text { next funding bid. A focus on generating long term } \\
\text { outcomes rather than accounting for current }\end{array}$ \\
& expenditure, activities and outputs. \\
& $\begin{array}{l}\text { Responsibility of individual groups and organisations } \\
\text { to adapt to the changing external environment by } \\
\text { developing sustainable funding strategies and } \\
\text { diversifying funding sources. }\end{array}$ \\
\hline sdaptation of individuals and to enhance &
\end{tabular}

Note: Adapted from Lister (2004)

But the apparent enthusiasm for new forms of finance, for sustainable funding and for an exploration of trading and earning within the voluntary and community sector comes up 
p.36. Understanding the idea of 'grant dependency' in the voluntary and community sector

sharply against the flipside of investment: an apparently recalcitrant, risk averse culture within the sector as a whole which seems stubbornly resistant to consider forms of finance 'beyond grants'. Bolton and Kingston (2006; p. 12) note this in a recent snapshot of the emerging market for new finance:

The Baseline Report for the Adventure Capital Fund refers to high levels of demand for patient capital. However, it also provides some words of caution about the cultural challenge new forms of financing pose charities and other voluntary organisations (emphasis added).

Although I have identified an emergent set of new discourses around voluntary and community sector finance, and have attempted to set this within a particular ideational context, it is clear that this does not yet provide a fully convincing account of how and why the specific notion of 'grant dependency' has filtered into conventional discussions of the sector and may yet form new 'prevailing wisdom'.

\section{Conclusion - towards a research agenda on shaping the voluntary and community sector 'field'}

Much of the writing about new forms of finance appears to come from enthusiastic protagonists, and involves detailing the growing sophistication of a range of new finance approaches. The argument for why this agenda has yet to be embraced more widely throughout the sector is pitched in cultural terms, by reference to what some appear happy to label as 'grant dependency'. But thus far, the discussion of how this agenda has emerged is somewhat descriptive and apolitical. There seems to be little discussion of what this might more fundamentally mean for the structure and development of the voluntary and community sector. It says little about the 'political' implications of new finance, sustainable funding and 'grant dependency', in terms of questions such as:

- $\quad$ what agendas for the future direction of the sector are being promoted and why? In particular, how does this discourse relate to a wider project of making the voluntary and community sector more 'business-like' and market-oriented?

- what interests might best be served by such agendas?

- what cultural, social and ideological resources are drawn upon to make the case for 'sustainable funding' and against 'grant dependency'?

- to what extent is this discourse challenged, and what can this tell us about the contested internal nature of the voluntary and community sector?

As a step towards addressing some of these questions, two particular approaches may be worth further exploration, though these by no means exhaust the possibilities.

The notion of 'ideational' or 'discursive institutionalism' in political science has recently been developed in order to overcome the relative neglect of the role of ideas in shaping change in political institutions and strategies. This suggests that the emergence and circulation of ideas can have subsequent material effects by shaping decisions, actions and strategies, whether or not the ideas have particular merit in themselves. For example, Watson and Hay (2003) suggest that policies designed to respond to the challenge and/or opportunity of globalisation rely more on the belief that globalisation exists and creates 
certain imperatives over and above the (contested) evidence for this belief. They argue that New Labour's 'Third Way' strategy is thus predicated on a necessitarian 'logic of no alternative'. Rather than the reality of globalisation affecting the subsequent political programme, the programme was devised as if the world was globalised. The discursive construction of globalisation appears to have become more significant than the patchier evidence that makes up the 'reality' of globalisation in the first place.

Transferring this debate to the voluntary and community sector, it is worth examining further the contention that beliefs surrounding the existence of 'grant dependency' are perhaps more significant than the evidence for its existence. The evidence base for the idea of a 'grant dependent' culture looks thinner than the circulation of the idea might warrant. Of greater interest is the extent to which particular decisions, policies and programmes are predicated on a belief that there is such a culture. The emergence of a more challenging funding environment may also play a potential role as an immutable imperative which creates the need for accommodation and adaptation by the voluntary and community sector.

A second, more sociological, approach to understanding the rise and implications of the idea of 'grant dependency' asks what this debate might tell us about the nature of the voluntary and community sector itself; that is how it is constituted, how it operates, how it is understood and what are its dynamics. Drawing on Bourdieu's social theory, the suggestion here is that the voluntary and community sector may be usefully understood as a relatively self-enclosed, contested and competitive 'field', shaped by participants with access to different levels of different forms of capital, and underpinned by a pre-reflexive 'habitus' or understanding of how the social world operates and where participants 'fit in'. Language and ideas will play a role here, in how the 'field' is conceptualised and understood, and how this might be changing. The key research question here concerns the extent to which a conventional, deep-seated understanding and ethos in the sector (that is, a 'voluntary sector habitus', which may be characterised, accurately or not, as 'grant dependent') is open to challenge and change. The emergence of the idea of 'grant dependency' then is a good test of how the voluntary and community sector 'field' is changing, and how its 'habitus' may also be undergoing change.

\section{Acknowledgements}

This is a revised version of a paper given at the 11th NCVO-VSSN Researching the Voluntary Sector Conference and at the Social Policy Association Conference, both in 2006. I would like to thank Del Fletcher, Steven Marwick, Sarah Pearson and Peter Wells for helpful comments and suggestions.

* Correspondence Address: Rob Macmillan, Centre for Regional Economic and Social Research, Sheffield Hallam University, Unit 10, Science Park, Howard Street, S1 1WB, UK. Email: r.macmillan@shu.ac.uk. 
p.38. Understanding the idea of 'grant dependency' in the voluntary and community sector

\section{References}

Blackmore, A. (2005) Your Future: the consultation findings. London: NCVO.

Bolton, M. and Kingston, J. (2006) Approaches to financing charitable work: tracking developments - January 2006. West Malling, Charities Aid Foundation.

Carrington, D. (2005) Financing the voluntary and community sector - future prospects and possibilities, in: Robb, Campbell (ed), Voluntary Action: meeting the challenges of the $21^{\text {st }}$ century, pp. 95-119. London, NCVO.

Chapman, T., Brown, J., Crow, R. and Ward, J. (2006) Facing the Future: a Study of the Impact of a Changing Funding Environment on the Voluntary and Community Sector in the North East of England. Middlesbrough, Social Futures Institute, Teesside University.

Dean, H. and Taylor-Gooby, P. (1992) Dependency Culture: The explosion of a myth. Hemel Hempstead, Harvester Wheatsheaf

Dobrowolsky, A. and Jensen, J. (2005) Social investment perspectives and practices: a decade in British politics, in: Powell, M., Bauld, L. and Clarke, K. (eds) Social Policy Review 17: Analysis and debate in social policy, 2005, pp 203-230. Bristol, Policy Press.

Finance Hub (2005) Financing Voluntary and Community Sector Activity Finance Hub Business Plan.

Giddens, A. (1998) The Third Way: The Renewal of Social Democracy. Cambridge, Polity Press.

Griffiths, M., Wilding, K. and Jochum, V. (2005) Voluntary Sector Strategic Analysis 2005/06: An overview of the operating environment and strategic drivers for UK voluntary organisations. London, NCVO.

HM Treasury (2002) The Role of the Voluntary and Community Sector in Service Delivery: A Cross Cutting Review. London, HM Treasury.

Home Office (2004) Change Up - Capacity Building and Infrastructure Framework.London, Home Office.

Kendall, J. (2003) The Voluntary Sector. London, Routledge.

Lister, R. (2004) The Third Way's Social Investment State in: Lewis, J. and Surender, R. (eds) Welfare State Change: Towards a Third Way?, pp 157-181. Oxford, Oxford University Press.

Macmillan, R. (2004) Shaping the future... The development of voluntary and community sector infrastructure in County Durham. County Durham, One Voice Network.

Palmer, H. and Mornement, A. (2005) From Asking to Earning - Experiences of Trading. RISE - Regional Infrastructure for the South West.

Shutt, J. and Kumi-Ampofo, F. (2005) Changing Funding Programmes: Impact on the Work of the Voluntary and Community Sector and Consequences for the Yorkshire and Humber Economy. Leeds, Yorkshire and Humber Regional Forum.

Unwin, J. (2004) The Grantmaking Tango: Issues for funders. London, Baring Foundation.

Watson, M. and Hay, C. (2003) The discourse of globalisation and the logic of no alternative: rendering the contingent necessary in the political economy of New Labour. Policy and Politics, 31, 3, 289-305.

Wainwright, S., Clark, J., Griffith, M., Jochum, V. and Wilding, K. (2006) The UK Voluntary Sector Almanac 2006. London: NCVO. 